\title{
Capital markets in Central and Eastern Europe: two selected cases
}

\author{
Luminiţa NICOLESCU \\ The Bucharest University of Economic Studies, Bucharest, Romania \\ luminicolescu@yahoo.com \\ Florentin Gabriel TUDORACHE \\ The Bucharest University of Economic Studies, Bucharest, Romania
}

\begin{abstract}
The evolution of mutual funds in terms of their inflows and outflows is seen as a good indicator of the capital markets' performance in different countries. At individual level, investors substantiate their buying decisions on the past performance information and invest asymmetrically in funds with very good performance in the previous periods. Numerous studies, mainly conducted in US, illustrate that mutual fund flows are highly dependent on the funds' previous performance, as a common behavior of investors resides in looking for highly performing funds than to get rid of poorly performing ones. This paper investigates the flows of funds into and out of Slovakian and Hungarian mutual funds during the period 2007-2014 and has as main purpose to analyze the behavior of investors in mutual funds in these two emerging financial markets. The analysis focuses on identifying patterns in investors' decision making processes and on checking the similarity of their behavioral patterns and illustrating differences among the two. Given the peculiarities of the studied period, a financially turbulent period, the paper also tries to evaluate if and how the financial crisis affected the investing behavior of Slovakian and Hungarian investors, based on the evolution of inflows and outflows of funds in a period that comprises the global financial crisis and the present period in which recovery has started.
\end{abstract}

Keywords: mutual funds, Central and Eastern Europe, investors' behaviour, Hungary, Slovakia.

\section{Introduction}

This paper provides a thorough examination of the evolution of money flows in mutual funds in two emerging capital markets, namely Hungary and Slovakia. The analysis is conducted on five categories of mutual funds in the period 2007-2014, an interval that comprises the period of the recent global economic crisis. The conducted examinations in the two countries are used to make a comparison between investors' behavior in the two emerging financial markets. Findings illustrate that there are both similarities but also differences in the behavior of Hungarian and Slovak investors in the financial markets.

These are presented in the paper. The paper is organized as follows: section one presents the main literature body looking at flow-performance relationship and related aspects, section two describes the research methodology for both countries, section three depicts the main research findings in a comparative manner and the conclusions summarize the comparative findings, illustrating similarities and differences between the two countries. 


\section{Literature review}

In order to characterize the behavior of investors in capital markets, we will look first at the interaction between investors and mutual funds, as presented by literature. This is related to investors' decision to select and invest in funds on the one hand and to exit funds on the other hand, and the corresponding evolutions of flows in different categories of funds. There is a large body of literature that focuses only on equity funds (Ippolito, 1992; Gruber, 1996; Ferreira, Keswani, Miguel and Ramos, 2012; Kim, 2013) and most of it refers to US market (Navone, Pagani and Pantos, 2012; Li Ma, 2013, Kim, 2013). There are less studies referring to bond funds (Chen and Qin, 2015; Zhao, 2005) and most of them consider the US market as well.

There are also a few studies in other developed markets than US (Ferreira, Keswani, Miguel and Ramos, 2012), but studies focusing mainly on emerging markets are very few. The Brazilian mutual market was studied by Varga and Wengert (2010) and Varga (2011), while Ferreira, Keswani, Miguel and Ramos (2012) studied 28 countries among which some were emerging capital markets (India, Indonesia, Malaysia, Poland, Taiwan, Thailand). The Romanian mutual funds market was analyzed by Tudorache, Nicolescu and Lupu (2015a) and the Hungarian mutual funds market was looked at by Tudorache, Nicolescu and Lupu (2015b) while other studies looked at the relationship with the economic growth (Miron, Dima and Vasilache, 2009) and the context of social responsibility (Dima and Vasilache, 2013).

Most of those studies showed that fund performance is one main criterion in the decision making of investors. Chen and Qin (2015) found that investor flows in corporate funds chase recent fund returns. However, the predictability on investors' flows is dependent on the fund performance flow persistence (Li Ma, 2013). Ferreira, Keswani, Miguel and Ramos (2012) observed that investors' behavior is different from one country to another according to their level of knowledge and information and that in certain countries investors are more sensitive to the flow-performance sensitivity than in others. The level of information and knowledge of investors can be dependent on advertising of funds such as the ones that have recently outperformed (Ferreira, Keswani, Miguel and Ramos (2012) or other communication methods, such as word of mouth (Andrei, Zaiţ, Vătămănescu and Pînzaru, 2017).

The convexity of the flow-performance relationship is another issue debated in the literature. The literature shows that there are differences in the flow-performance convexity for different types of mutual funds, as well as for different countries. The convexity between flow and performance was found to be valid for equity funds (Sirri and Tufano, 1998; Ferreira, Keswani, Miguel and Ramos, 2012; Navone, Pagani and Pantos, 2012). For bond funds the flow-performance relationship is not convex as "corporate bond fund investors react to poor performance as sensitively as to good performance" (Chen and Qin, 2015, p. 3). The results of the study conducted by Ferreira, Keswani, Miguel and Ramos (2012) in 28 countries illustrated that the convexity of the flow-performance relationship decreases with the level of development of the country. For instance, they found that less developed countries present levels of convexity of the flow-performance relationship three times larger than developed countries.

This paper adds to the existing literature evidence from emerging markets on the flow- performance relationship as an explanation of the investors' behavior. The paper also introduces a comparative perspective to the analysis. 


\section{Data and research methodology}

This paper investigates the evolution of the open-ended mutual funds from two emerging countries from Central and Eastern Europe, namely Hungary and Slovakia. Data collection included the measurement of mutual funds' performance through the unit value of the funds and their returns, as well as the size of the funds, measured through their net assets. The data on mutual funds was drawn from the BAMOSZ (The Fund Managers' Association from Hungary) for Hungary and from SASS (The Fund Managers' Association from Slovakia) for Slovakia. BAMOZ has 23 members (investment management companies) who administer 581 mutual funds, while SASS has 21 members who administer over 500 mutual funds. The data was collected for the period January 2007 to December 2014 and all the investment funds marketed in the two capital markets were studied, with the exception of funds managed by foreign societies. For both countries data was grouped on 5 major categories of mutual funds as presented in Table no. 1.

Table 1. Mutual funds studied in Hungary and Slovakia, 2007-2014

\begin{tabular}{|c|c|c|c|c|c|c|}
\hline $\begin{array}{c}\text { Types of } \\
\text { funds }\end{array}$ & $\begin{array}{c}\text { Equity } \\
\text { funds }\end{array}$ & $\begin{array}{c}\text { Mixed } \\
\text { funds }\end{array}$ & $\begin{array}{c}\text { Other } \\
\text { funds }\end{array}$ & $\begin{array}{c}\text { Monetary } \\
\text { funds }\end{array}$ & Bond funds & Total \\
\hline Hungary & 126 & 45 & 125 & 46 & 52 & 394 \\
\hline Slovakia & 224 & 44 & 113 & 35 & 89 & 505 \\
\hline
\end{tabular}

Source: Authors' own research.

The relationship between the fund flow and performance was studied with the following regression model:

$F L O W_{i, t}=\alpha+\beta_{1} L_{n T N A} A_{i, t-1}+\beta_{2} S T D_{i, t-1}+\beta_{3} F L O W_{i, t-1}+\beta_{4} F_{L O W C A T_{s, t-1}}+\beta_{5} R K_{i, t-1}+$ $\beta_{6} S Q R K_{i, t-1}$

where FLOW $\mathrm{i,t}$ refers to the flow of money in the current month, while $i$ counts the funds we analyzed and $t$ stands for the moment in time for each observation. The explanatory variables are the following: LnTNA $_{i, t-1}$ is the logaritm of the net assets (size of the fund) in the previous month, $\mathrm{STD}_{\mathrm{i}, \mathrm{t}-1}$ is the standard deviation of returns in the previous month, FLOW $\mathrm{i}_{\mathrm{i}, \mathrm{t}-1}$ represents the flow of new money in the previous month, FLOWCAT $_{\mathrm{s}, \mathrm{t}-1}$ is the growth in percentage of the new money of the entire fund category, $\mathrm{RK}_{\mathrm{i}, \mathrm{t}-\mathrm{1}}$ stands for rank in the fund category it belongs to and $\mathrm{SQRK}_{\mathrm{i}, \mathrm{t}-\mathrm{1}}$ is the square of the rank in the fund category it belongs to.

The regressions were performed for each fund, meaning 394 regressions for Hungary and 505 regressions for Slovakia. The results of the regressions are presented in the following section.

\section{Empirical results}

The results of the regressions performed for each fund in our panel are included in this section. Here are presented the regression coefficients ( $\beta_{1}$ to $\left.\beta_{6}\right)$ that are significant at least at $5 \%$ for the independent variables considered.

Regression coefficient $\beta_{1}$ - Logarithm of the net assets in the previous month (LnTNA $A_{i, t-1)}$ A first observation is that for Hungary the percentage of mutual funds for which the relationship between the fund flow (as dependent variable) and the logarithm of the net assets in the previous month (size of the fund) is significant and varies from $18 \%$ for "bond 
funds" to $29 \%$ for "monetary funds". In Slovakia, the percentage of mutual funds for which the size of the fund influences the subsequent flows varies from $19 \%$ for "equity funds" to $34 \%$ to "monetary funds". Overall, in Slovakia the level of significance of variance of net assets in the previous month on flows is slightly higher than in Hungary, as it can be noticed in Figures no. 1a and $1 \mathrm{~b}$.

(1a) Hungary
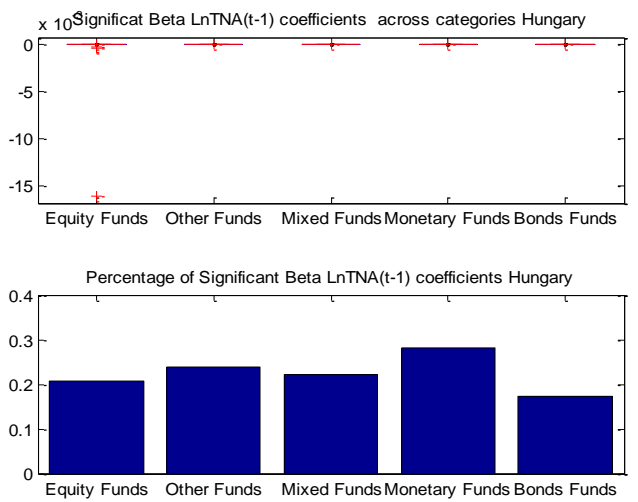

(1b) Slovakia
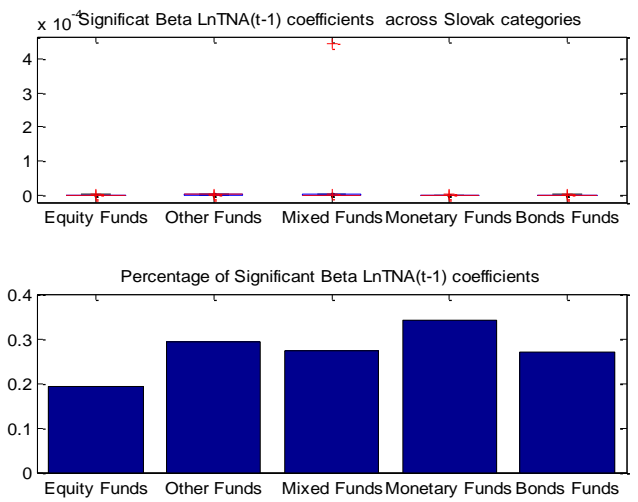

PICBE $\mid 600$

\section{Figure 1. Regression coefficient $\boldsymbol{\beta}_{1}$ for funds in Hungary and Slovakia, $2007-2014$}

Source: Authors' own research.

In Hungary it was noticed an increase in flows of the low risk fund categories in spite of decreasing size. We could consider that the significant coefficient is biased by multicollinearity in our regressions, i.e. by the fact that investors are keen to place their investments in low risk funds even though the level of net assets was decreasing (as a result of the general decline in asset prices globally). The Slovak investor prefers to invest in high risk funds when they have an increasing trend in their size.

There are similarities and differences between the two countries. Besides the "equity funds" category for which the direction of the relationship was not clear in both countries, the other fund categories have different directions of the relationship in each of the countries. However, the Slovak investor seems more mature and/or more informed than the Hungarian investor and when he invests in mutual funds it appears that he takes the size of the funds into consideration in the traditional way (investing in larger and increasing funds) more than the Hungarian investor does.

Regression coefficient $\beta_{2}$ - Standard deviation of returns in the previous month $\left(S_{T D} D_{i, t-1}\right)$ Coefficient $\beta_{2}$ describes the risk associated to the investment. In Hungary, the relationship was significant at $5 \%$ for only $22 \%$ of the funds in all categories as presented in Figure 2 a. "The monetary funds" category had positive relationships for $26 \%$ of all monetary funds, illustrating an increase in the subscriptions at an increase in risk of returns, a rather surprising result. A possible explanation might be that for monetary funds the returns were more volatile due to the movements in interest rates (which decreased during the financial crisis). This result suggests that Hungarian investors increase their participations in "monetary funds", as their returns change, but we need to consider that in a situation of decreasing prices, people behave differently.

In Slovakia, the volatility of returns constitutes an influencing factor for 109 open ended funds from a total of 505 funds, representing $21.5 \%$ of funds, with variations in the significance of the relationships from one category of funds to the other. The similarity 
between Hungary and Slovakia is that $\beta_{2}$ is significant for a similar percentage of the total funds $(22 \%$ and $21.5 \%)$, indicating that risk is overall taken into consideration to the same extent by investors from the two countries. Another similarity is that for "monetary funds" where $\beta_{2}$ has positive values in both countries, indicating a rather atypical situation: the flow increases with the increase in the previous risk levels of "monetary funds".

An explanation can be that in both countries the Central Banks had unconventional monetary policies during the financial crisis that envisaged to relaunch their economies by decreasing the Central Bank interest rate and consequently the interest rates of commercial banks decreased. Such declines in interest rates determined a movement of capital from the private financial markets (such as stocks) towards government securities (such as bonds and Treasury bills).

(2a) Hungary
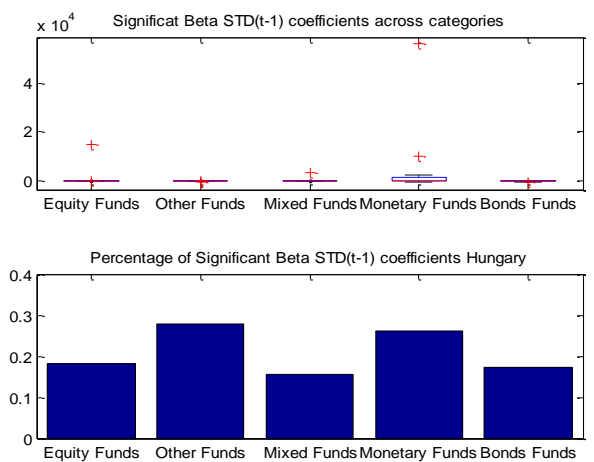

(2b) Slovakia
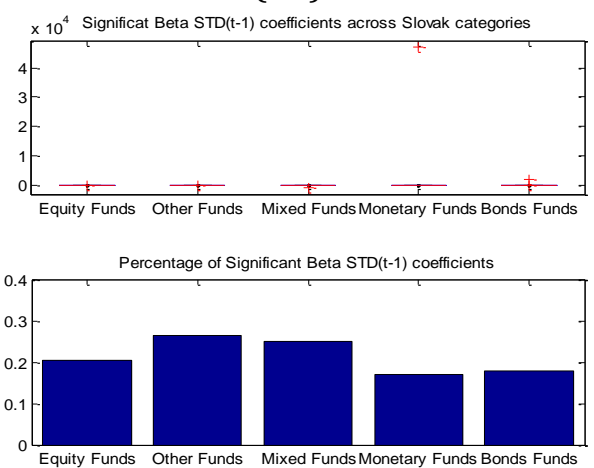

PICBE | 601

Figure 2. Regression coefficient $\beta_{2}$ for funds in Hungary and Slovakia, 2007 - 2014

Source: Authors' own research.

\section{Regression coefficient $\beta_{3}$ - Flow of new money in the previous month (FLOW $\left.W_{i, t-1}\right)$}

The variation of the new money in the previous month $\left(\mathrm{FLOW}_{\mathrm{i}, \mathrm{t}-1}\right)$ is the predictor with the highest level of significance among all indepdent variables in the studied regression for both Hungary and Slovakia (see Figure no. 3).

In Hungary, for the "mixed funds" category $\beta_{3}$ was significant for $93 \%$ of the funds (the highest percentage) and for the "bond funds" for $80 \%$ of the funds (the lowest percentage), while in Slovakia the "mixed funds" category had the lowest percentage of significant relations among all fund categories, but still high (61.8\%), and the "monetary funds" had the highest percentage of significant $\beta_{3}(88.5 \%)$.

(3a) Hungary
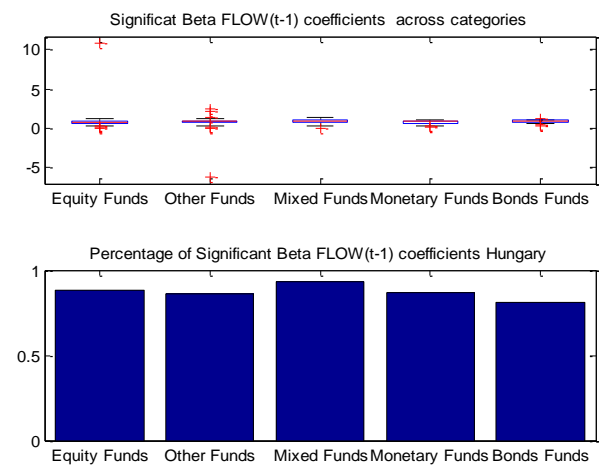

(3b) Slovakia
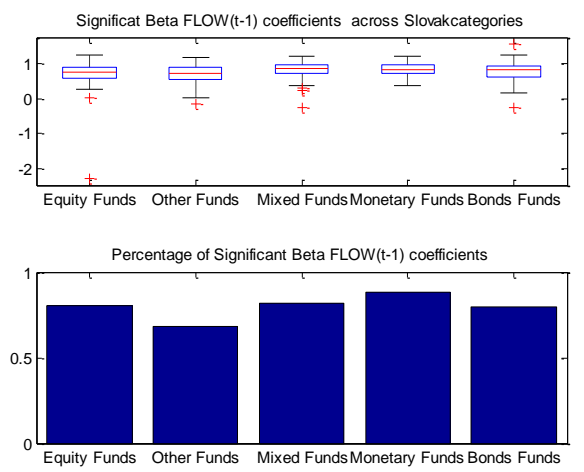

Figure 3. Regression coefficient $\beta_{3}$ for funds in Hungary and Slovakia, 2007 - 2014 
Source: Authors' own research.

Regression coefficient $\beta_{4}$ - Growth in percentage of new money for the entire fund category (FLOWCAT $T_{s, t}$ )

This variable describes the infusion of new capital in a fund category and therefore, the evolution in terms of size for the respective fund category.

In Hungary, the growth in percentage of the new money of the entire fund category $\left(\right.$ FLOWCAT $\left._{\mathrm{s}, \mathrm{t}-1}\right)$ is a factor with significance for a low number of funds in the categories "equity funds", "mixed funds" and "monetary funds", the percentage of funds for which the relationship is significant varying among 5\% and 11\% and illustrating a weak influence of the factor for these fund categories.

(4a) Hungary
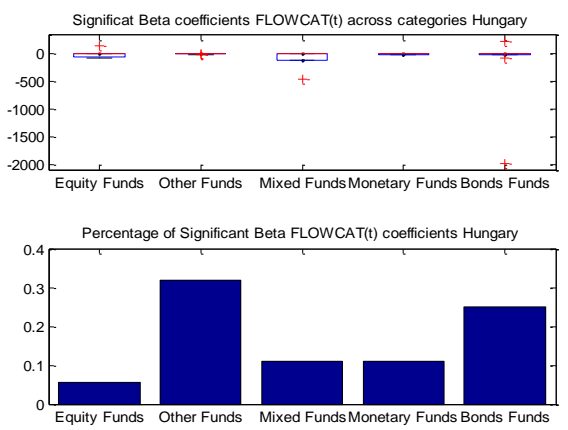

(4b) Slovakia
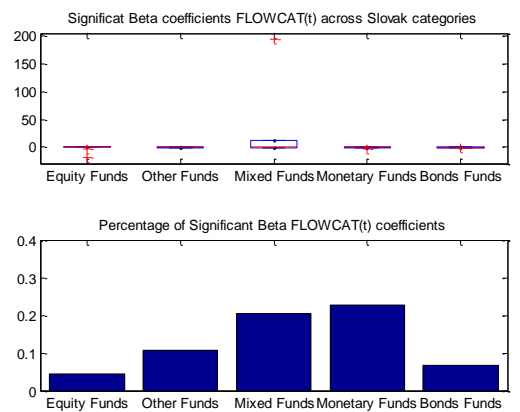

Figure 4. Regression coefficient $\boldsymbol{\beta}_{\mathbf{4}}$ for funds in Hungary and Slovakia, 2007 - 2014

Source: Authors' own research.

In Slovakia, for three fund categories ("equity funds", "other funds" and "bond funds"), the regression coefficient $\beta_{4}$ is not a significant predictor, as the percentage of funds with significant relationships between variables are $4.4 \%, 10.6 \%$ and $6.7 \%$, respectively. In the case of "mixed funds", $20.4 \%$ of them have a significant $\beta_{4}$ coefficient, while in the case of "monetary funds" $22.8 \%$ of them have a significant coefficient. Although these percentages are not very high, they illustrate the existence of a relationship between the variables - see Figure $4 \mathrm{a}$.

The differences between the two countries consist of the type of funds for which the percentage growth of the fund category is a good predictor of the present flow ("bond funds" and "other funds" for Hungary, and "monetary funds" and "mixed funds" for Slovakia). In Slovakia the investor has an expected economically oriented behaviour as he invests more in funds that attract more capital ("mixed funds"). In Hungary, on the other hand, for both "bond funds" and "other funds", the behaviour of the investors is inclined to invest more capital in these funds categories when the market contracts. This behaviour related to the movement of capital from the high risk fund categories to low risk fund categories, even when the low risk categories register decrease in size, simply because in an ecnomic crisis period the investor feels safer to invest in low risk fund categories.

\section{Regression coefficient $\beta_{5}-$ Rank in the fund category $\left(R K_{i, t-1}\right)$}

Coefficient $\beta_{5}$ can be thought of as a measure of performance, as it describes the position of individual funds in their category in the previous period in terms of returns. See figure no 5. In Hungary, for both categories "equity funds" and "other funds", $\beta_{5}$ is significant for a low proportion of the funds - 8\%, respectively $13 \%$-, with the direction of signs (plus or minus) balanced in terms of numbers. This indicates that for these fund categories, the relationship 
between fund flow and the rank in the fund category is insignificant for the majority of funds (over 85\%). This illustrates that either investors are uninformed and/or they do not take into consideration this factor when making the investment decision.

In Slovakia, for the fund categories with high risk, there are significant relationships for a small part of the funds $(7.9 \%$ for "other funds", 9\% for "mixed funds" and $10.7 \%$ for "equity funds"). For fund categories with low risk, the percentage of funds with significant $\beta_{5}$ is larger - $20 \%$ for "monetary funds" and $22.4 \%$ for "bonds funds" (see Figure no. $5 \mathrm{~b}$ ).

\section{(5a) Hungary}
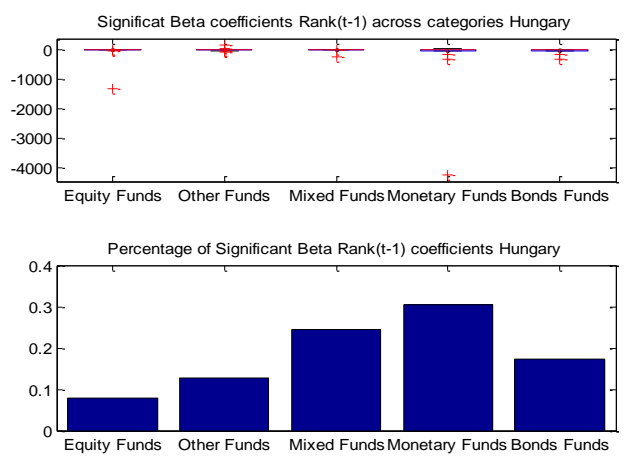

(5b) Slovakia

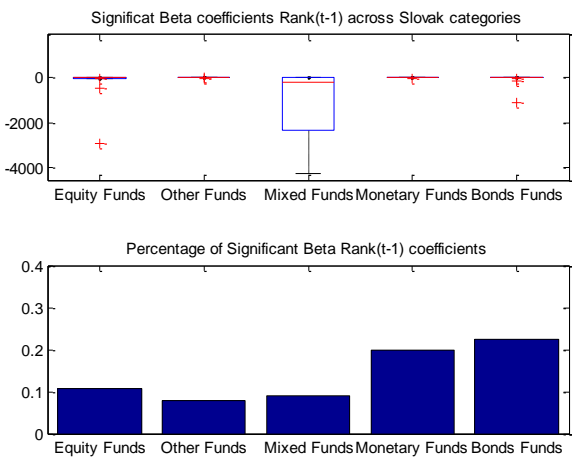

Figure 5. Regression coefficient $\boldsymbol{\beta}_{5}$ for funds in Hungary and Slovakia, 2007 - 2014

Source: Authors' own research.

It can be concluded that this factor was not a very influential factor for the flow of most mutual funds (especially the high risk funds) in neither of the countries, Hungary or Slovakia in the studied period. The fund categories for which a higher performance in terms of a better position in the fund category determined an increase in fund flows were the low risk funds both in Hungary and in Slovakia, indicating a certain decisional maturity of investors who move towards low risk funds in a economically turmoiled period.

Regression coefficient $\beta_{6}$ - Square of the rank in the fund category (SQRK $\left.K_{i, t-1}\right)$

In Hungary, the situation of $\beta_{6}$ is similar with the one of $\beta_{5}$, as the coefficient was significant for less than $10 \%$ of the "equity funds" - see Figure no. 6 . In Hungary, the significant $\beta_{6}$ coefficient were negative in the case of both low risk fund categories - "monetary funds" $(32 \%)$ and "bond funds"(16\%) -, illustrating that fund flows increase once the fund's squared rank in its category decreases. This result might mean either that we have uninformed investors or investors who wished to invest in safer funds in spite of the fact that these funds' performance was declining, with the aim of decreasing their risk exposure in a period of high volatility.

In Slovakia there are significant only a relatively small percentage of $\beta_{6}$ coefficients: varying from $9.3 \%$ for "equity funds" to $19.1 \%$ for "bond funds". See Figure $6 \mathrm{~b}$.
(6a) Hungary
(6b) Slovakia 

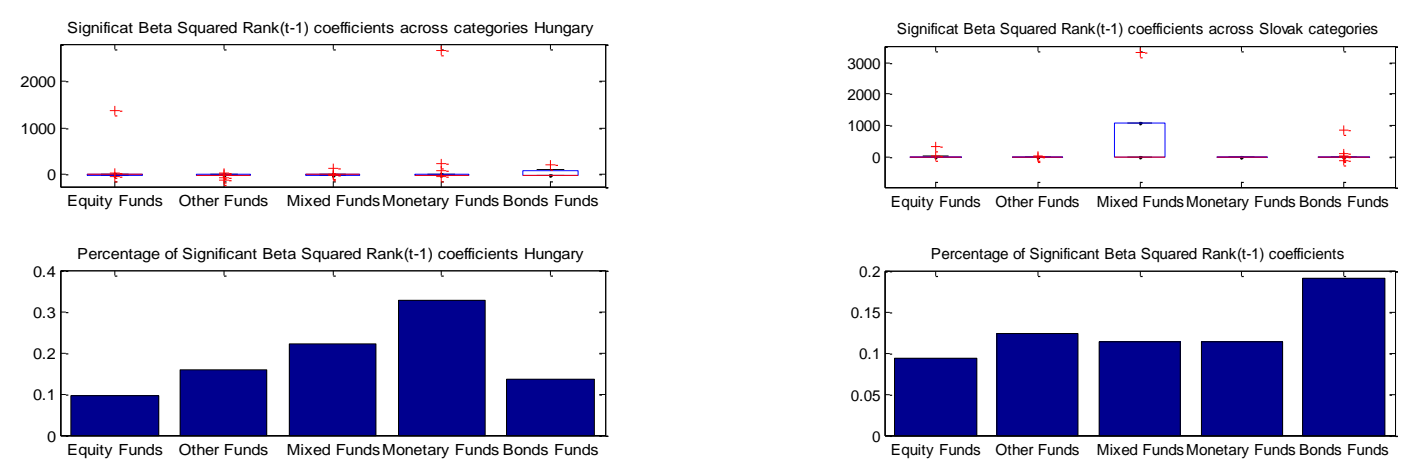

PICBE $\mid 604$

Figure 6. Regression coefficient $\beta_{6}$ for funds in Hungary and Slovakia, 2007 - 2014

Source: Authors' own research

The comparison between Hungary and Slovakia shows a rather small influence of the square of the rank in the fund category on flows for most funds categories in both countries. Only low risk funds seem to have this as an influencing factor in both countries, but without clear direction in Slovakia and with a rather negative influence in Hungary.

\section{Conclusion}

The analysis of the two mutual fund markets and behaviour of investors in the two countries, Hungary and Slovakia, illustrate both similarities and differences. For both countries the regression equation was valid for more than $90 \%$ of all funds (based on $\mathrm{p}$ values of F-statistic), illustrating an exiting influence of the independent variables on the dependent variable.

The analysis of the size of the fund conveyed through net assets in the previous month leads to the conclusion that this factor is an influencer of flows in both countries (for around $20-35 \%$ of all funds), but the direction of influence is rather mixed. However, Slovak investors seem to take this information into consideration at a higher extent than Hungarian investors when fund units are acquired, by investing in larger and increasing funds.

The examination of the standard deviation of returns shows that risk is an influencing factor of the investors' acquision behaviour in both countries (21-22\%of all funds). An atypical behaviour of investing in "monetary funds" was observed in both countries investors put more money in the riskier "monetary funds". This result might suggest that investors attempt to diminish their risks in difficult economic periods, by investing in low risk funds, even when their risk increase in time, because they are perceived as being less risky than high risk funds.

The fund flows in the previous month is the factor that influences the most the current flows in both countries (for $68-100 \%$ of all funds in each country). Investors in both Hungary and Slovakia invest only in funds that attracted previously more capital.

Exploring the influence of the percentage growth of the fund category on flows it can be concluded that, this is an influencing factor for a low number of funds in both countries. While in Slovakia the investor invests more in funds that attract more capital (e.g. "mixed funds"), in Hungary investors tend to invest when there is less capital invested on overall in those funds categories (e.g. "bond funds"; "other funds"). It might be that the average Hungarian investor collects less information about the market evolution and the capital 
invested previously in the mutual funds market or that the investor tends to move towards less risky mutual funds in spite of their decreasing size, because they prefer to be safe.

The rank and the square rank of funds in their categories are not very influential factors for flows in neither of the two countries. It seems that investors in both countries pay attention to performance in terms of position only for the investments that are safe, for which the returns are more or less guaranteed.

PICBE | 605

It can be concluded that, the behaviour of investors in the Slovak and Hungarian mutual funds market is similar in that, that the factors considered are influencers for both the evolution of flows and for the way investors make decisions. However, considering the differences between countries, investors in Slovakia seem to be more informed and to make more documented decisions that follow the traditional economic logic to a larger extent than Hungarian investors. At the same time, we cannot ignore the fact that capital markets in both countries were volatile over the studied period and in such periods investors' behaviour is more difficult to be explained as it does not follow classical economic criteria.

\section{References}

Andrei, A.G., Zaiț, A., Vătămănescu, E.-M., and Pînzaru, F. (2017). Word of mouth generation and brand communication strategy: findings from an experimental study explored with PLS-SEM. Industrial Management \& Data Systems, 117(1),

BAMOSZ -The Fund Managers' Association from Hungary, http://www.bamosz.hu/, retrieved May 2015.

Chen Y. and Qin N. (2015). The Behaviour of Investor Flows in Corporate Bond Mutual Funds. Management Science, Forthcoming. Available at SSRN: http://dx.doi.org/10.2139/ssrn.2022059, accessed December 2016.

Dima A.M. and Vasilache S.N. (2013). An analysis between the link of emerging markets MNES's reputation and social corporate responsibility, in Leonard, L and Gonzalez Perez, MA (eds.), Principles and Strategies to Balance Ethical, Social and Environmental Concerns with Corporate Requirements, Book Series: Advances in Sustainability and Environmental Justice, 12, 51-66.

Ferreira, M.A., Keswani A., Miguel A.F. and Ramos S.B. (2012). The flow-performance relationship around the world, Journal of Banking\&Finance, 36,1759-1780.

Forthcoming.

Gruber, M.J. (1996.) Another puzzle: The growth in actively managed mutual funds. Journal of Finance, 51, 783-810.

Hungary. The Proceedings for the international conference The Future of Europe, ISSN 2392-861.

Ippolito, R.A. (1992). Consumer reaction to measures of poor quality: Evidence from the mutual fund industry, Journal of Law and Economics, 35, 45-70.

Kim. M.S. (2013). Changes in Mutual Fund Flows and Managerial Incentives, Social Science Research Network, Retrieved from http://papers.ssrn.com/sol3/papers.cfm?abst

Li Ma. (2013). Mutual Fund Flows and Performance: A Survey of Empirical Findings, available at https://www.wiwi.hu-berlin.de/de/professuren/bwl/cofi/research/

Miron D., Dima A.M. and Vasilache S.N. (2009), Indexes of regional economic growth in post-accession Romania, Romanian Journal of Economic Forecasting, 11(3), 138-152. 
Navone M., Pagani M. and Pantos T.D. (2012). The Determinants of the Convexity in the Flow-Performance Relationship, Journal of Index Investing, 3 (2), 81 - 95, Retrieved from https://opus.lib.uts.edu.au/handle/10453/22658, ract_id $=1573051$.

SASS - The Fund Managers' Association from Slovakia, http://www.ass.sk/, retrieved May 2015.

Sirri E. and Tufano. P. (1998),.Costly search and mutual funds flows, Journal of Finance, 53(5), 1589-1622.

Tudorache F.G., Nicolescu L. and Lupu R. (2015a). Evolution of mutual funds in Romania: performances and risks, Romanian Journal of Economic Forecasting, 18(4), 180-197.

Tudorache F.G., Nicolescu L. and Lupu R. (2015b). The performance of mutual funds in

Varga G. (2011). Mutual Fund Flow and Past Information: Is the Brazilian Investor Smart, available at http://www.anpad.org.br/admin/pdf/FIN568.pdf,

Varga G. and Wengert M. (2010). The Growth and Size of the Brazilian Mutual Fund Industry, Retrieved from https://www.researchgate.net/publication/228241214 _The_Growth_and_Size_of_the_Brazilian_Mutual_Fund_Industry workingpapers/li-fundflow-performance-2013.pdf, accessed December 2016.

Zhao X. (2005). Determinants of flow into retail bond funds, Financial Analysts Journal, 61, 47-59. 